\title{
História
}

das Ciências

e Educação

\section{Epistemologia kuhniana e transformações científicas da homossexualidade}

\author{
Kuhinian epistemology and the scientific transformations \\ of homosexuality
}

CRISTIANO FIGUEIREDO DOS SANTOS

Universidade Federal do Mato Grosso do Sul | UFMS

MARIUCIY MENEZES DE ARRUDA

Universidade Federal do Mato Grosso do Sul | UFMS

PATRÍCIA SANDALO PEREIRA

Universidade Federal do Mato Grosso do Sul | UFMS

VERA DE MATTOS MACHADO

Universidade Federal do Mato Grosso do Sul | UFMS

Resumo O artigo busca evidenciar a epistemologia kuhniana e na análise foi utilizado o exemplo da homossexualidade. Trata-se de um trabalho teórico, de natureza qualitativa que pretende contribuir com práticas educativas em ciências de modo a possibilitar melhor entendimento sobre a epistemologia kuhniana, sexualidade e a relação ciência-sociedade. Ao fornecer tal análise, consideramos ter explicitado um modelo útil e concreto da proposição kuhniana e que pode ser utilizado no ensino de ciências especialmente por potencialmente contribuir para a diminuição de discriminações sociais e com noções mais democráticas de sociedade.

Palavras-chave Thomas Kuhn - sexualidade - ciências.

\begin{abstract}
This article seeks to highlight the Kuhnian epistemology and the analysis uses the example of homosexuality. This is a theoretical work, of a qualitative nature that aims to contribute to educational practices in science in order to enable a better understanding of Kuhnian epistemology, sexuality and the science-society relationship. In providing such analysis, we consider to have spelled out a useful and concrete model of the Kuhnian proposition, which can be used in science education especially because it potentially contributes to the reduction of social discrimination and with more democratic notions of society.
\end{abstract}

Keywords Thomas Kuhn-sexuality-science. 


\section{Introdução ${ }^{1}$}

A sexualidade humana pode ser entendida um componente social e cultural capaz de aglutinar discussões que se estendem para o campo da medicina, do direito, da educação, da psicologia e da economia, entre outros exemplos. Os saberes sobre sexualidade, incluindo aqueles sobre os mecanismos que regulam os processos de atração afetiva e sexual entre seres humanos, não são dominados por nenhuma área específica do saber.

Modelos que se voltam para a maneira de viver as afetividades, contudo, têm historicamente validado e mantido uma maneira de organização social com base em uma leitura que tem fundamentos em visões religiosas e mesmo

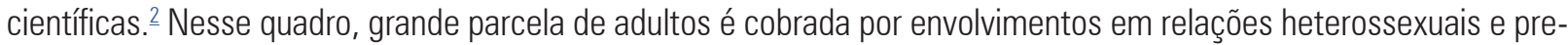
ferencialmente monogâmicas, o que resultaria, entre outras coisas, numa prática em que a relação poderia ser reduzida ao coito vaginal e teria como fundamento a reprodução. 0 problema com essa perspectiva é que ela, muitas vezes, não leva em consideração que as expressões da sexualidade não se restringem a finalidades exclusivamente reprodutivas.

Se tomarmos como medida essa maneira de entender a vivência das afetividades, deixaremos de considerar que esse modelo não serve, por exemplo, à grande maioria das pessoas idosas, de pessoas com objetivos de vida que não incluem reprodução (celibato, por exemplo), pessoas com algumas deficiências ou dificuldades físicas/mentais ou mesmo porque não serve a todas as etapas da vida. 0 modelo em questão não serve, especialmente, para as pessoas que desejam outra(s) do mesmo gênero..$^{\underline{3}}$

Homossexual é o termo utilizado na atualidade para caracterizar uma pessoa que deseje outras do mesmo sexo ou gênero. Essa designação não incorpora o caráter de doença mental como ocorria no início do século XX, ainda que possamos dizer que permanecem rastros desse traço patologizante validado pela ciência no passado. Talvez esse fato, juntamente com questões religiosas que ainda não foram totalmente desvinculadas da sexualidade, tenha contribuído para que a homossexualidade seja considerada ainda hoje crime em alguns países, com a condenação podendo resultar em prisão perpétua ou mesmo pena de morte. ${ }^{4}$

Neste artigo buscaremos evidenciar a epistemologia kuhniana e nossa análise se faz por meio do uso do exemplo acerca da homossexualidade, passando pelas etapas de gênese, construção, crise e desconstrução científica no que se refere à sua interpretação enquanto uma patologia. Trata-se de um trabalho teórico, de natureza qualitativa que pretende contribuir com práticas educativas em ciências. Mendonça 5 indica que não seria exagerado afirmar que Kuhn determinou a agenda da filosofia da ciência na segunda metade do século XX e destaca que um de seus livros é o maior best-seller da história da epistemologia, tendo causado uma verdadeira revolução nas questões filosóficas referentes à ciência.

Pensar a relação entre a epistemologia kuhniana e os locais científicos ocupados pela homossexualidade talvez não seja um exercício tão linear e rapidamente efetuado. E é no intuito de contribuir com esse exercício que este trabalho se apresenta. Concordamos com Mendonça,$\underline{\underline{6}}$ por exemplo, quando indica que não podemos nos esquivar de questões que relacionam o envolvimento da ciência com valores democráticos e a responsabilidade social dos cientistas. 0 ensino de ciências, assim como de sua história, pode e deve permitir reflexões acerca da forma como a sexualidade tem sido entendida, especialmente se puder contribuir para a diminuição de discriminações sociais. Ao inserir uma perspectiva que discuta a natureza da ciência nesse debate, acreditamos que tanto discussões sociais quanto possibilidades de trabalhar o ensino de ciências avançam.

Assim, o presente texto intenciona menos tentar indicar respostas sobre alguma natureza da homossexualidade e mais pensá-la como exemplo útil e concreto de alvo da atividade científica proposta por Kuhn sem deixar de considerar sua relação com a sociedade. Para tanto, na primeira parte do texto faremos uma exposição histórica das categorias nas quais esse conceito já esteve alocado, a fim de ilustrar as mudanças na interpretação acerca dele e suas relações com a ciência no contexto de cada época. Na segunda parte do trabalho nos utilizamos dos textos de Ostermann e de Moreira e Massoni ${ }^{8}$ para relacionar a epistemologia kuhniana e o desenvolvimento científico com a história da homossexualidade a partir de quatro conceitos-chave: paradigma, ciência normal, revolução científica e incomensurabilidade. Por fim, na última seção, apresentamos algumas considerações finais. 


\section{Homossexualidade: comportamento, pecado, crime, doença, condição}

Na Antiguidade o desejo e as relações entre pessoas do mesmo sexo parecem ter sido motivos de inquietações, entretanto, sem vinculação com a carga semântica que a palavra homossexualidade apresenta nos contextos atuais. Ferrari e Caetano ${ }^{9}$ informam que para os gregos

O prazer com rapazes ou moças não resultava em classificação, tanto uma quanto outra forma de orientação era livre, permitida pelas leis e opiniões e encontrando suporte nas instituições, como, por exemplo, as militares, as pedagógicas e até mesmo vivenciadas em ritos e festas religiosas. Eram culturalmente valorizadas pela literatura, cantadas nos versos, de modo que esta servia para refletir e fundamentar seu valor.10

Embora aceitas, as relações não eram tidas como indiferentes, de forma que os papéis assumidos na relação (erasta e erômero - homem mais velho e seu aprendiz) é que a tornavam moralmente válida. As relações sexuais entre homens desempenhavam uma função iniciática e eram extremamente regulamentadas, constituindo uma minoria não aceita aqueles que mantinham práticas exclusivas com homens. ${ }^{11}$ Na Roma Clássica, a relação entre homens era tolerada sob uma série de condicionantes que envolviam a família e interesses econômicos. .12

Por outras razões e sob formas diferentes, os romanos e gregos consideravam totalmente normal que homens tivessem relações sexuais com outros homens e, também, com mulheres. A regra segundo a qual a virilidade consiste em assumir o papel ativo na relação sexual era comum à moral das duas civilizações. As dicotomias "macho/fêmea", "ativo/passivo" definiam os papéis sociais, o acesso ao poder e a posição de cada indivíduo segundo seu gênero e sua classe..$^{13}$

0 cristianismo, herdeiro da tradição judaica, ao introduzir uma nova dicotomia homossexual-heterossexual, retira 0 foco do exercício da virilidade e do poder nas relações e o dirige para as pessoas envolvidas na relação, transformando a heterossexualidade no único comportamento suscetível de ser natural e, por conseguinte, normal. "Sob influência do cristianismo, o Império Romano empenha-se na repressão das relações entre pessoas do mesmo sexo"..14

A repressão das relações entre pessoas do mesmo sexo tem início na Idade Média, quando a Igreja passaria a considerar como pecado todo ato sexual desprovido de função procriativa. $\frac{15}{5}$ período da escolástica vai ter papel fundamental na introjeção da imagem negativa das relações entre pessoas do mesmo sexo porque será comparada "aos pecados mais abjetos, tais como canibalismo, bestialidade ou ingestão de imundices". 16

[...] o prazer sexual é legítimo somente na medida em que não é acompanhado de um ato suscetível de entravar a reprodução. Com efeito, a masturbação é vigorosamente condenada, assim como qualquer comportamento sexual com a espécie errônea (bestialismo), o sexo errôneo (homossexualidade) ou o órgão errôneo (sexo oral ou anal) [...]. A Escolástica vai construir, assim, uma norma que continua modelando a ideologia sexual ocidental: o coito heterossexual do tipo conjugal e a submissão da mulher na relação sexual, cujo único objetivo consiste na inseminação procriadora.17

Outro fator apontado tanto por Borrillo $0^{18}$ quanto por Silva Jr. ${ }^{\frac{19}{}}$ como influente na hostilidade às relações entre pessoas do mesmo sexo é a grande peste negra que se deu na Europa e dizimou mais de um terço da população no século XIV. Foi justamente a agressão da peste associada à baixa expectativa de vida da população que "tornou a heterossexualidade necessária para garantir a procriação, fazendo surgir diversas leis contrárias às práticas homoafetivas". 20 A perseguição às pessoas que se relacionavam com outras do mesmo sexo acentuou-se entre os séculos XIII e XV e "até o final do século XVIII, todas as disposições penais, sem exceção, fazem referência ao mito de Sodoma para justificar a punição de gays e lésbicas".11

A sodomia só referenciava homens que exercessem a prática em outros homens ou em mulheres (isso porque 0 entendimento corrente era o de que as mulheres não podiam sentir prazer sexual), $\underline{22}$ contudo, na Idade Média, a prática 
era classificada de duas maneiras, sendo considerada perfeita (quando efetuada por dois homens) ou imperfeita (quando envolvia duas mulheres). $\stackrel{23}{ }$ De qualquer forma, enquanto por um viés religioso a sodomia foi considerada pecado, logo depois, por um viés do Estado, ela passaria a ser considerada crime.

Relacionado ao surgimento das populações e aos aspectos políticos e econômicos ligados a elas, o sexo, no século XVIII, se torna questão de polícia, e não no sentido de policiamento, como repressão da desordem, mas sim "como majoração ordenada das forças coletivas e individuais". ․ㅡ Entram em cena, por exemplo, questões como taxa de natalidade, idade do casamento, nascimentos legítimos e ilegítimos, frequência de relações sexuais, entre outras.

É verdade que já há muito tempo se afirmava que um país devia ser povoado se quisesse ser rico e poderoso. Mas é a primeira vez que, pelo menos de maneira constante, uma sociedade afirma que seu futuro e sua fortuna estão ligados não somente ao número e à virtude dos cidadãos, não apenas às regras de casamento e à organização familiar, mas à maneira como cada qual usa seu sexo.. $\frac{25}{5}$

Em meados do século XVIII, portanto, a sexualidade tinha sido tomada como um tema que dizia respeito à Igreja e ao Estado. $\underline{26}$ Uma das possibilidades mais importantes para a estruturação de controle dos bens materiais e dos processos de herança passava pelo comando e pela manutenção da expressão da sexualidade. 0 sujeito homossexual surge no século XIX, ${ }^{27}$ período marcado pela preocupação com a classificação de 'anormalidades'를 no qual a caça às sexualidades periféricas resultaria em uma especificação dos indivíduos. Se a sodomia era um tipo de ato interdito e seu autor não passava do sujeito jurídico desse ato, o homossexual torna-se um personagem, de modo que "a homossexualidade apareceu como uma das figuras da sexualidade quando foi transferida, da prática da sodomia, para uma espécie de androgenia interior, um hermafroditismo da alma. 0 sodomita era um reincidente, agora o homossexual é uma espécie". 29

Antes de considerarmos o surgimento do que foi denominado "homossexualismo" (sic), ${ }^{30}$ cabe chamar atenção para o fato de que, em algumas sociedades, é possível encontrar a prática da sodomia como algo descolado de uma identidade homossexual. Alguns homens não se identificariam como homossexuais porque, neste caso, não assumiriam um papel feminino, posto destinado a quem se deixa penetrar. $\frac{31}{3}$

A história do termo "homossexualismo" tem início no final do século XIX, $\underline{32}$ num contexto médico-psiquiátrico para referenciar homens e mulheres com afeto e sexualidade voltados para pessoas do mesmo sexo. Os sujeitos são não somente pecaminosos, criminosos, mas também doentes mentais. ${ }^{33}$ Nesse cenário, as sexualidades que fugiam do formato cristão do casamento monogâmico e do modelo heterossexual adulto foram enquadradas como anômalas e, assim, merecedoras de classificação e policiamento, já que passam a ser caracterizadas como distúrbios sexuais..$^{34}$

Médicos e a medicina, de forma geral, se apropriam de um campo que era anteriormente dominado pela Igreja católica, "porque 'conhecem' o que é 'certo' e o que é 'errado' e, dessa forma, teriam a obrigação de conduzir o homem no caminho correto da sexualidade, respeitando a natureza humana. $\underline{35}$

Ao apresentar o que denomina de amplo esboço do campo da sexologia, Russo ${ }^{36}$ informa que a primeira etapa dessa ciência se deu entre o final do século XIX e primeiras décadas do século XX. A maior parte da literatura sexológica da segunda metade do século XIX estrutura-se, segundo a autora, em torno do "homossexualismo" (também denominado na época de inversão, sentimentos sexuais contrários e sexualidade antipática).

Contudo, nesse contexto, o domínio do campo da sexualidade pela medicina se viu contraposto pelo campo do direito em função de discussões sobre a legalidade da descriminalização, uma vez que "a produção de uma ciência da sexualidade tinha como objetivo descriminalizar o comportamento perverso, transformando-o em questão médica lembro que os primeiros sexólogos eram médicos. Ocorria, portanto, uma disputa entre a medicina e o direito, em que a primeira acabou levando vantagem". $\underline{37}$

A medicina arrogou-se, assim, a incumbência de solucionar o que era tido como um problema que atingia a sociedade - os homossexuais - por meio de ações médico-corretivas. Embora médicos não sejam, senso estrito, cientistas e nem sua atividade profissional usual tenha objetivos voltados para a produção do conhecimento, a forma como 0 
saber médico é produzido e transmitido reveste-se de características da atividade científica ${ }^{38}$ e teve influência ímpar na história do "homossexualismo" de tal maneira que, na virada do século XIX para o XX, ele era compreendido em termos biológicos e a medicina identificava três possíveis causas da doença: a hereditariedade, os defeitos congênitos e os desequilíbrios hormonais. $\frac{39}{3}$

Nos anos finais da década de 1940 e início dos anos 1950, depois de um período de declínio das discussões no pós-guerra, os debates sobre sexualidade voltam a aflorar especialmente nos Estados Unidos com as publicações do biólogo Alfred Kinsey. 0 tema teve continuidade, em grande parte, com a publicação conjunta do médico Willian Masters e da psicóloga Virginia Johnson marcando a sexologia moderna e impulsionando o debate no campo de uma discussão fisiológica da função sexual. 40

Uma das marcas desse século é o início de um movimento para a desconstrução de identidades afetivo-sexuais estigmatizadas e de represálias contra a patologização do que era entendido na época como "homossexualismo". Um movimento de inclusão civil dessa forma de expressão da sexualidade ganha força e são fundamentais, nesse contexto, os movimentos feministas dos anos 1960 e 1970, o pensamento pós-estruturalista e a epidemia de Aids nos anos 1980 que problematizaram noções vigentes de corpo, sexo, sexualidade e direitos. ${ }^{41}$ Os livros publicados nos Estados Unidos por Masters e Johnson, por exemplo, encontram recepção em um momento de grande ebulição cultural e política, de questionamento e ruptura com os valores tradicionalmente associados à família nuclear e ao que ela implicava em termos de comportamento moral e circunscrição da sexualidade. ${ }^{42}$

É diante desse cenário que em 1973 o "homossexualismo" é retirado da lista de doenças mentais da Associação Americana de Psiquiatria e, em 1985, o Conselho Federal de Medicina, no Brasil, declara o enquadramento de casos que envolviam "homossexualismo" em uma categoria diferente da anterior (outras circunstâncias psicossociais). Na sequência, não oficialmente em 1990 e de maneira formal em 1992, a Organização Mundial de Saúde segue os passos da Associação Americana de Psiquiatria e, em 1999, o Conselho Federal de Psicologia, no Brasil, estabelece normas de atuação para psicólogos afirmando que a homossexualidade não constitui doença, nem distúrbio e nem perversão. ${ }^{43}$ As décadas de 1970, 1980 e 1990 são, assim, marcadas por graduais revisões de classificações patologizantes do chamado "homossexualismo" em diversas instituições médico-científicas ao redor do mundo.

Embora noções biomédicas que explicariam as causas da hoje nominada homossexualidade sejam levantadas desde o início do século XX, incluindo anormalidade em órgãos genitais, anomalias da dentição, pés, cabelo, combinações anormais de hormônios e volume do hipotálamo, ${ }^{\underline{4}}$ nenhuma dessas pesquisas teve significação científica para estabelecer correlações aceitáveis. ${ }^{45}$ No cenário de todas essas investigações, cabe reproduzir o que afirma Moita, $\underline{46}$ sendo "o facto de a homossexualidade poder eventualmente ser determinada geneticamente não implica que ela tenha configurações patológicas" e ainda que "nenhuma das teorias ancoradas na biologia ganhou expressão significativa - pois o próprio facto de a replicação de todos esses estudos nada ter provado de conclusivo permite refutar qualquer uma delas". .7

Sobre o que tentamos expor aqui, finalizamos esta seção coadunando com o pensamento de Moita ${ }^{48}$ uma vez que também entendemos não haver, por si só, algo de negativo em pesquisar as possíveis causas da homossexualidade, contudo, "enquanto as causas da heterossexualidade não forem um elemento de análise clínica haverá sempre uma diferença no valor atribuído a cada vivência". $\underline{49}$

\section{Epistemologia kuhniana e desenvolvimento científico}

0 trabalho de Thomas Kuhn é importante para a ciência contemporânea especialmente em função de suas ideias precursoras sobre desenvolvimento científico explicitadas em seu livro publicado em 1962, A estrutura das revoluções científicas. 0 autor elabora críticas ao positivismo lógico na filosofia da ciência e à historiografia tradicional e reconhece o caráter construtivo, inventivo e não definido do conhecimento. Na perspectiva de Ostermann, "esta posição, mais tarde, configurar-se-á como o que existe de consenso entre os filósofos contemporâneos da ciência". .00 


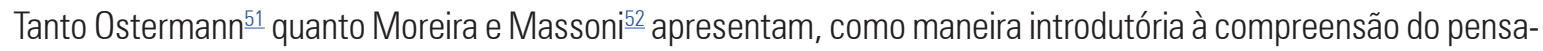
mento de Thomas Kuhn quatro conceitos-chave: paradigma, ciência normal, revolução científica e incomensurabilidade. 0 progresso científico, na visão de Kuhn, é sintetizado por Moreira e Massoni ${ }^{53}$ no seguinte esquema aberto: "pré-ciência - ciência normal (dentro de um paradigma) - crise - revolução científica (mudança descontínua de paradigma) - nova ciência normal (dentro de um novo paradigma) - nova crise - nova revolução..." 0 texto de Ostermann ${ }^{54}$ chama a atenção ainda para o fato de que é no período de revoluções cientificas que se faz a ciência extraordinária e de que os episódios extraordinários são marcados por anomalias.

É a partir dessa ideia que tentaremos aproximar aspectos da história da homossexualidade com as etapas do desenvolvimento científico propostas por Thomas Kuhn a partir das noções apresentadas por Ostermann ${ }^{55}$ e por Moreira e Massoni, $\underline{56}$ que coincidem em muitos pontos.

A partir do esquema apresentado por Moreira e Massoni, $\underline{57}$ é importante reter o que é definido como pré-ciência, etapa primeira no modelo e que não se repete posteriormente. A pré-ciência é caracterizada como

a atividade desorganizada e diversificada que precede o amadurecimento científico caracterizado pela adesão a um paradigma. É essa adesão que identifica a ciência madura. É ela que funciona como critério de demarcação entre ciência e não ciência, ou seja, o critério que na perspectiva kuhniana, distingue a ciência da pseudociência é a inexistência de um paradigma capaz de apoiar uma tradição de ciência normal..$\underline{58}$

Na etapa pré-científica existe certa desorganização e, principalmente, poderíamos dizer que não existe vigente um paradigma, termo que explicitaremos mais detalhadamente adiante, mas que poderíamos resumir aqui como uma matriz disciplinar que propicia o advento do consenso, observável em revistas especializadas e manuais de ensino. $\mathrm{Na}$ relação proposta, a medicina, primeiro por meio da sexologia e depois da psiquiatria, teria tido importância fundamental na atividade pré-científica, no sentido de poder organizar um conjunto de saberes, tidos a partir daí como científicos, com projeção no tratamento dado às sexualidades, mas, especificamente, sobre as sexualidades entendidas, no contexto, como desviantes, entre elas, o "homossexualismo".

Ao se apropriar dos saberes de uma ciência da sexualidade, paulatinamente a medicina institui um campo pré-científico sobre o entendimento acerca do "homossexualismo", demarcando terreno. Discussões sobre pecado e crime não interessam a essa ciência, e sim o julgamento do que é ou não doença, critério que, nesse campo, passa a ser um terreno discursivo próprio/apropriado da/pela medicina.

0 início do paradigma que atribuiu uma condição patológica às relações homossexuais nas ciências médicas deu-se no século XIX quando se instala e se efetiva a crença na distinção biológica e/ou psicológica entre normais e anormais, e, consequentemente, entre homossexuais e heterossexuais. Tanto foi necessária a instituição de marca da influência médica na definição dessas práticas que a medicina do século XIX acaba por cunhar o termo "homossexualismo". $\underline{59}$

São os médicos que vão reivindicar o poder de sua autoridade [...]. O exercício desse poder vai transformar o discurso sobre homossexuais de "crime", "pecado" para "doença" e, também, vai alterar o tratamento da homossexualidade, pois se o crime e o pecado merecem punição, a doença exige a "cura". Com a criação do termo homossexual e com a transformação do homossexual em doente, abre-se possibilidade de cura através do tratamento "médico-pedagógico". $\underline{60}$

Assim, no contexto da ciência normal, aquela que se pratica dentro de um paradigma, o "homossexualismo" emerge como objeto de investigação científica. A crença de que é um desvio da norma e que, portanto, requer medidas médico-científicas para sua normalização apresenta-se, aí, como um paradigma científico. A imagem da ciência normal, concebida por Kuhn, é a de uma atividade extremamente conservadora, cuja rigidez é condição necessária para o progresso científico. 11

Na explanação kuhniana, a ciência normal forma um binômio indissociável com o paradigma, ou seja, aquela só é normal porque está sob a égide desse. $\underline{62}$ "Paradigma" é um termo que recebeu críticas em função de sua polissemia 
e da diversidade de acepções ao longo da obra (conceito posteriormente aperfeiçoado ${ }^{63}$ ) e que, sem querer fazer uma discussão específica sobre a questão, neste trabalho será assumido como o conjunto de exemplares das realizações científicas que sustentam a ciência normal.

Os paradigmas, ou exemplares, propiciam o advento do consenso - visível nas revistas especializadas, bem como nos manuais de ensino - acerca dos fundamentos da prática científica. Sob sua posse, cessam os debates de ordem metodológica (quais os meios adequados de investigação), de ordem epistemológica (o que deve ser investigado e quais soluções devem ser alcançadas) e de ordem ontológica (qual a natureza das entidades investigadas). Uma vez findadas essas discussões basilares, os cientistas podem despender seu tempo em questões mais específicas..$\underline{64}$

Thomas Kuhn dedica parte de seu texto a explorar aspectos relativos à importância das publicações específicas na consolidação de paradigmas e na orientação do trabalho de cientistas. Neste sentido, indica que

\begin{abstract}
Quando um cientista pode considerar um paradigma como certo, não tem mais necessidade, nos seus trabalhos mais importantes, de tentar construir seu campo de estudos começando pelos primeiros princípios e justificando o uso de cada conceito introduzido. Isso pode ser deixado para os autores de manuais. Mas, dado o manual, o cientista criador pode começar suas pesquisas onde o manual a interrompe e desse modo pode concentrar-se exclusivamente nos aspectos mais sutis e esotéricos dos fenômenos naturais que preocupam o grupo. [...] Suas pesquisas já não serão habitualmente incorporadas a livros [...]. Em vez disso, aparecerão sob a forma de artigos breves, dirigidos apenas aos colegas de profissão, homens que certamente conhecem o paradigma compartilhado e que demonstram ser os únicos capazes de ler os escritos a eles endereçados. $\frac{65}{5}$
\end{abstract}

Entendemos que a materialização do estabelecimento do "homossexualismo" como um paradigma se deu, em nossa perspectiva, com o registro desse termo no Manual de Classificação Internacional de Doenças (CID) que, segundo a lógica proposta por Kuhn, teria passado a nortear o trabalho de cientistas da área e explicitado ser desnecessária a discussão dos princípios aí estabelecidos, já que "os cientistas trabalham a partir de modelos adquiridos por meio da educação ou da literatura a que são expostos subsequentemente, muitas vezes sem conhecer quais as características que proporcionaram o status de paradigma comunitário a esses modelos".$\underline{6}$

Os transtornos relacionados à sexualidade passaram a fazer parte da CID em 1949, em sua sexta edição (CID6), quando foi inaugurada uma seção dedicada aos transtornos mentais.. "Homossexualismos" masculino e feminino figuravam em uma categoria que reunia pedofilia, sodomia, exibicionismo, fetichismo e travestismo, entre outros. Como comportamentos não reprodutivos, compunham modelos de comportamentos desviantes. Esse registro foi mantido na CID até 1965 quando passou para a categoria "Desvio e Transtornos Sexuais - homossexualismo". $\underline{68} \mathrm{Na}$ CID-9 a noção de desvio sexual foi apresentada, mas somente na CID-10, em 1990, as parafilias foram denominadas como distúrbios da preferência sexual e parafilias. 0 desvio sexual representava uma espécie de distúrbio intermediário, entre as violações da ordem social e as falhas morais. Já o termo parafilia foi utilizado pela primeira vez em um livro sobre aberrações sexuais. $\cdot \frac{69}{}$

Assim, o consenso sobre o caráter patológico do "homossexualismo" expressado nos manuais médicos do século passado configuraria o estágio da ciência normal, que é caracterizada por pesquisa firmemente baseada em uma ou mais realizações científicas passadas e que "parece ser uma tentativa de forçar a natureza a encaixar-se dentro dos limites preestabelecidos e relativamente inflexíveis fornecidos pelo paradigma", 00 uma vez que "a tarefa da ciência normal consiste em realizar a 'promessa de sucesso' feita pelo paradigma". 11

Nesse cenário, se ocorre um fenômeno que não se ajusta aos limites do paradigma ele é, frequentemente, ignorado ou nem visto. Cientistas, nesse contexto, muitas vezes, mostram-se intolerantes com novas teorias e "a pesquisa científica normal está dirigida para a articulação daqueles fenômenos e teorias já fornecidos pelo paradigma".끄 Contudo, um paradigma pode não ser suficientemente forte para resistir a críticas a enigmas não resolvidos. 
Há períodos nos quais o quebra-cabeça da ciência normal fracassa em produzir os resultados esperados. Os problemas, ao invés de serem encarados como quebra-cabeças, passam a ser considerados anomalias, gerando um estado de crise na área de pesquisa - o chamado período de ciência extraordinária. $\underline{ }$

Essas crises podem terminar de três modos particulares, dos quais o mais interessante para Kuhn seria quando a crise se encerra pela emergência de um novo candidato a paradigma e com uma subsequente batalha por sua aceitação, $\underline{\underline{74}}$ pois se liga ao progresso da ciência e, diferentemente da ciência normal, está longe de ser um processo cumulativo obtido por articulação do velho paradigma.

Thomas Kuhn destaca o papel crucial que o sentimento de precariedade do funcionamento do paradigma tem nas revoluções científicas, atuando como pré-requisito.

[...] as revoluções científicas iniciam-se com um sentimento crescente, também seguidamente restrito a uma pequena subdivisão da comunidade científica, de que o paradigma existente deixou de funcionar adequadamente na exploração de um aspecto da natureza, cuja exploração fora anteriormente dirigida pelo paradigma. Tanto no desenvolvimento político como no científico, o sentimento de funcionamento defeituoso, que pode levar à crise, é um pré-requisito para a revolução. $\frac{75}{}$

Se o paradigma do "homossexualismo" assumia que a condição do homossexual era patológica, então, poderíamos supor que a promessa desse paradigma deveria resultar em encontrar a cura dessa condição. 0 enigma que colocou em xeque tal matriz disciplinar foi suficientemente forte para questionar a ausência dos resultados esperados e assim explicitar uma anomalia, enfraquecendo o paradigma vigente em questão.

Além disso, Kuhn chama a atenção para o desenvolvimento político do sentimento de mau funcionamento do paradigma como um pré-requisito para a revolução, podendo levar à crise. Cabe destacar assim os movimentos sociais e políticos fervilhantes dos anos 1960 e 1970 que atuaram advogando pela liberação sexual de práticas não reprodutivas e não conjugais no interior desse cenário.

0 abandono do paradigma do "homossexualismo" parece ter sido concretizado na revisão de dois importantes instrumentos normalizadores sobre o que é ou não considerado doença (mental): a já mencionada Classificação Internacional de Doenças (CID) e o Manual Diagnóstico e Estatístico de Transtornos Mentais (DSM). Conquanto 0 DSM seja de responsabilidade da American Psychiatric Association (APA), anteriormente denominada American Medico-Psychological Association, o CID é de responsabilidade da Organização Mundial de Saúde. Nas edições DSM III e III-R a homossexualidade aparece como parafilia, e na CID-10 o quadro de parafilias excluiu quaisquer distúrbios relacionados à homossexualidade e às questões resultantes de orientação sexual. Na vindoura CID-11, os transtornos psicológicos e comportamentais associados ao desenvolvimento e orientação sexual podem vir a ser completamente excluídos na proposta. $\frac{76}{}$

Ainda que esses dois instrumentos sejam inegavelmente importantes para a questão, cabe ressaltar que eles divergem em alguns aspectos. 0 DSM tem critérios que ensejam o fim da definição de certos comportamentos sexuais como patológicos em si mesmos, e a CID tem critérios mais diagnósticos e sistematizados. Além disso, o DSM-5 considera que a existência de determinado comportamento, na ausência de desconforto, não seja suficiente para caracterizar um transtorno parafílico, entretanto, os documentos da CID-11 não apontam para o mesmo grau de tolerância. Ademais, a CID-11 não despatologiza os comportamentos sexuais em si, mas apenas aqueles sem parceiro (masturbação) ou que envolvam parceiros consensuais. $\underline{\underline{ }}$

De forma geral, o entendimento que aparenta existir sobre a questão, a partir da revisão histórica destes instrumentos, DSM e CID, é o de que o tratamento médico das perversões sexuais (parafilias, transtornos de preferência sexual) evoluiu de um modelo de patologização de todo comportamento sexual não reprodutivo a um modelo que consagra 0 bem-estar sexual e a responsabilidade envolvendo, portanto, o consenso nos relacionamentos. 
A materialização do que consideramos ser o abandono do paradigma do "homossexualismo" nos manuais médicos não deve ser pensado, contudo, como um evento isolado e que teria emergido repentinamente. Uma revolução científica é caracterizada pela mudança descontínua de um paradigma para outro. Kuhn adverte que "frequentemente um novo paradigma emerge - ao menos embrionariamente - antes que uma crise esteja bem desenvolvida ou tenha sido explicitamente reconhecida". ${ }^{78}$ Nesse sentido, destacamos, para ficar com alguns exemplos, que mesmo com a aceitação do paradigma do "homossexualismo", Sigmund Freud e Sandor Ferenczi opuseram-se à discriminação de homossexuais e ao uso da psicanálise como cura na década de 1920 e que Jaques Lacan foi o primeiro psicanalista pós-freudiano a romper definitivamente com a perseguição contra homossexuais na International Psychological Association. $\underline{79}^{-}$

É no contexto da concomitância entre pesquisas que aderem (investigação científica normal) e que não aderem ao paradigma vigente (investigação científica extraordinária) que se institui a ciência extraordinária, premissa do progresso científico.

Quando os cientistas não conseguem mais esquivar-se das anomalias que subvertem o paradigma ao qual aderiram, começam as investigações extraordinárias, ou de ciência extraordinária, que finalmente os conduzem a um novo conjunto de compromissos, a uma nova base para a prática da ciência. $\stackrel{80}{ }$

Conforme indicado anteriormente, a partir dos anos 1960 o paradigma do "homossexualismo" como doença fundada em bases biológicas passa a ser questionado e é, finalmente, refutado e abandonado. Emerge uma visão sobre as (homos)sexualidades que, se não desconsidera as bases biológicas do corpo como matéria de expressão sexual, não se furta a considerar que as expressões da sexualidade têm forte componente cultural e social. Abandona-se o sufixo "-ismo" (que pode denotar doença) e passa-se a utilização do sufixo "-dade" (que pode denotar situação). Emerge 0 paradigma da homossexualidade. As ciências humanas se apresentam para o debate de questões em um cenário que era, até então, domínio da medicina e das ciências biológicas. Kuhn atesta que

É exatamente porque a emergência de uma nova teoria rompe com uma tradição da prática científica e introduz uma nova dirigida por regras diferentes, situada no interior de um universo de discurso, também diferente, que tal emergência só tem probabilidades de ocorrer quando se percebe que a tradição anterior equivocou-se gravemente..$\underline{\underline{B 1}}$

Ao incorporar problematizações resultantes, por exemplo, dos movimentos feministas e homossexuais, assim como 0 avanço das teorizações acerca do gênero que se deram nos anos 1970, 1980 e 1990, os debates sobre sexualidade puderam ser pensados a partir de outras perspectivas que, se não foram ignoradas anteriormente, não tinham tido expressão suficiente para questionar a tradição anterior. Durante o período de transição, "0 antigo paradigma e 0 novo competem pela preferência dos membros da comunidade científica, e os paradigmas rivais apresentam diferentes concepções de mundo",, 22 de modo que "Há fatores sociológicos e psicológicos envolvidos nesse processo que é de persuasão e conversão, não de compulsão" .․ㅗ

Kuhn indica que "a recepção de um novo paradigma requer com frequência uma redefinição da ciência correspondente. Alguns problemas antigos podem ser transferidos para outra ciência ou declarados 'não-científicos'". .44 Assim, chegamos à questão da incomensurabilidade de paradigmas, no qual "os proponentes dos paradigmas competidores praticam seus ofícios em mundos diferentes", $\underline{.5}$ sendo que "as diferenças entre paradigmas sucessivos são ao mesmo tempo necessárias e irreconciliáveis". .6 Apresentar-se-ia aí alguma disputa entre as ciências humanas e as ciências biológicas (que poderia, em tese, ser entendida como área de "estudos da sexualidade" e "estudos da sexologia", respectivamente) em torno do domínio dos saberes acerca da questão.

A adesão a um paradigma por cientistas inclui uma série de razões que podem nem se encontrar na esfera da

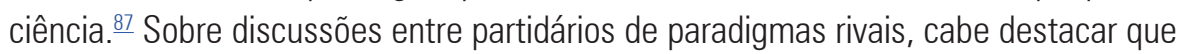


Cada paradigma vê o mundo como sendo composto de coisas diferentes. A maneira pela qual um cientista vê o mundo está determinada pelo paradigma ao qual aderiu e no qual está trabalhando. Justamente por isso não há como demonstrar logicamente a superioridade de um paradigma sobre outro. Exatamente por isso o objetivo de argumentos e discussões entre partidários de paradigmas rivais é a persuasão, não a compulsão. $\frac{88}{-}$

Diante de tal situação, um indivíduo ou grupo de cientistas pode relutar frente ao aparecimento e capacidade de atração de um novo paradigma, fazendo certa oposição e até mesmo se negando a aceitar determinadas proposições. Sobre escolas que são consideradas superadas, Kuhn informa que

Quando, pela primeira vez no desenvolvimento de uma ciência da natureza, um indivíduo ou grupo produz uma síntese capaz de atrair a maioria dos praticantes de ciência da geração seguinte, as escolas mais antigas começam a desaparecer gradualmente. Seu desaparecimento é em parte causado pela conversão de seus adeptos ao novo paradigma. Mas sempre existem alguns que se aferram a uma ou outra das concepções mais antigas: são simplesmente excluídos da profissão e seus trabalhos são ignorados. $\underline{\underline{89}}$

Nesse sentido, entendemos algumas produções relativamente recentes como exemplo de parte desse apego ao paradigma do "homossexualismo". Na intenção proposta neste trabalho, faremos esse paralelo com a ajuda de um trabalho ${ }^{90}$ que permite pensar, para além da psiquiatria, a medicina legal como um campo onde podemos encontrar resquícios do antigo paradigma. Em alguns livros de medicina legal é possível perceber interpretações da homossexualidade como desvio ou distúrbio, mesmo com o posicionamento atual de diversas instituições científicas.

Um dos livros apontados no estudo, de 2011, informa que o "homossexualismo", "uranismo" ou "pederastia" é uma das formas mais comuns de transtorno da identidade sexual. E que, além disso, o "homossexualismo feminino" pode ter como origem "a promiscuidade, o receio da gravidez, as decepções com os homens, os maus-tratos dos maridos, a educação moderna, a nova literatura, o comportamento masculino na atualidade [...] e a solidão, entre outros"..11

Outro livro, de 1991, alega que um indivíduo bem conformado sexualmente com o "uranismo" é um doente psíquico. Uma publicação de 2010 utiliza termos superados como "homossexualismo masculino ou uranismo ou pederastia" e "homossexualismo feminino ou safismo, lesbianismo ou tribadismo". Um livro de bolso, de 2009, voltado para concursos é outro exemplo que aponta o "homossexualismo" como distúrbio sexual, designando doenças ou transtornos que podem figurar como doenças mentais. No trabalho em questão, as autoras consideram que essas publicações "ainda estão numa elaboração arcaica e desconectada dos debates atuais"..$\underline{22}$

Da importância das ciências humanas e sociais na contribuição ao debate e entendimento das sexualidades, destaca-se que "foram os cientistas sociais que inauguram a concepção do homossexual como construção social [...]. A preocupação com a sociedade e com seus comportamentos sociais, afetivos, sexuais, acabou se prolongando para além das explicações cristãs e médicas, atingindo as ciências sociais e humanas [...]. $\underline{93}$

Diante do exposto, consideramos que a argumentação aqui desenvolvida pode contribuir no ensino de ciências ao possibilitar o entendimento sobre questões da sexualidade e de questões da epistemologia kuhniana, por meio da relação entre a história da homossexualidade e da exploração de conceitos como paradigma, ciência normal, revolução científica, incomensurabilidade, ciência extraordinária, crise e anomalia. 


\section{Considerações finais}

Ao assumir a proposição de Thomas Kuhn sobre a atividade científica consideramos ter encontrado no contexto científico da história da homossexualidade um exemplo que permite explorar conceitos-chave dessa epistemologia, tais como pré-ciência, paradigma, ciência normal, crise e anomalia, ciência extraordinária, revolução científica e incomensurabilidade. Esperamos poder contribuir, assim, com práticas educativas em ciências de uma dupla maneira: fornecendo um modelo que permita retirar possível abstração da proposição de Kuhn por meio da incorporação de registros históricos do caráter da homossexualidade enquanto categoria científica e também que permita refletir sobre a temática da sexualidade e os discursos que contribuem para discriminações e preconceitos, ponderando a relação ciência-sociedade.

Todavia, a intenção deste artigo é menos colocar um ponto final nessa questão e mais permitir que o paralelo proposto possa desdobrar-se em outras questões. Poderíamos pensar se, por exemplo, a partir da lógica kuhniana apresentada, estaríamos observando alguma disputa pelo domínio dos saberes sobre sexualidade entre ou no consenso das ciências biológicas e humanas. Ou, dito de outro modo, como se colocaria a questão da interdisciplinaridade sobre a discussão? Poderíamos tomar esse momento como outro período pré-revolucionário? São questões que podem nos levar a refletir e até mesmo a compreender melhor a proposta de atividade científica de Thomas Kuhn. Se assim for, nos daremos por satisfeitos com os objetivos propostos no texto.

\section{Notas e referências bibliográficas}

Cristiano Figueiredo dos Santos é doutorando em Ensino de Ciências na Universidade Federal de Mato Grosso do Sul. E-mail: professor.cristiano.biologia@gmail.com

Mariuciy Menezes de Arruda é técnica em Assuntos Educacionais na Universidade Federal de Mato Grosso do Sul.

Patrícia Sandalo Pereira é professora do Instituto de Matemática da Universidade Federal de Mato Grosso do Sul.

Vera de Mattos Machado é professora do Instituto de Biociências da Universidade Federal de Mato Grosso do Sul.

1 Agradecemos à Fundação de Apoio ao Desenvolvimento do Ensino, Ciência e Tecnologia do Estado de Mato Grosso do Sul (Fundect) pela concessão de bolsa de estudos ao primeiro autor e à Fundação Universidade Federal de Mato Grosso do Sul pelo apoio.

2 MOITA, Gabriela. A patologização da diversidade sexual: homofobia no discurso de clínicos. Revista Crítica de Ciências Sociais, n. 76, p. 53-72, 2006.

3 Idem.

4 LOMANDO, Eduardo; WAGNER, Adriana. Reflexões sobre termos e conceitos das relações entre pessoas do mesmo sexo. Revista Sociais e Humanas. Santa Maria, v. 22, n. 2, p. 113-123, 2009.

5 MENDONÇA, André Luis de Oliveira. 0 legado de Thomas Kuhn após cinquenta anos. Scientia Studia, v. 10, n. 3, p. 535-560, 2012.

$$
\text { Idem. }
$$

OSTERMANN, Fernanda. A epistemologia de Kuhn. Caderno Brasileiro de Ensino de Física, v. 13, n. 3, p. 184-196, 1996.

MOREIRA, Marco Antônio; MASSONI, Neusa Teresinha. Epistemologias do século XX: Popper, Kuhn, Lakatos, Laudan, Bachelard, Toulmin, Feyerabend, Maturana, Bohm, Bunge, Prigogine, Mayr. São Paulo: EPU, 2011.

9 FERRARI, Anderson; CAETANO, Marcio. A produção das homossexualidades nas ciências sociais e humanas. Gênero, v. 2, n. 2, p. 9-25, 2012.

10 Idem, p. 13-14.

11 BORRILLO, Daniel. Homofobia: história e crítica de um preconceito. Belo Horizonte: Autêntica, 2010.

12 Idem.

13 Idem, p.47.

14 Idem, p. 53.

15 SILVA JR., Assis Moreira. Diversidade sexual e inclusão social: uma tarefa a ser completada. Franca: Lemos e Cruz, 2014.

16 BORRILLO, 2010, op. cit., p. 53.

17 BORRILLO, 2010, op. cit.

18 Idem.

19 SILVA JR., 2014, op. cit. 
Idem, p. 91

BORRILLO, 2010, op. cit., p. 54.

LOMANDO; WAGNER, 2009, op. cit.

FERRARI; CAETANO, 2012, op. cit.

FOUCAULT, Michel. História da sexualidade: a vontade de saber. Tradução de Maria Thereza da Costa Albuquerque e J. A. Guilhon Albuquerque. $2^{\mathrm{a}}$ ed. São Paulo: Paz e Terra, 2015. p. 28.

FOUCAULT, 2015, op. cit., p. 29.

LOMANDO; WAGNER, 2009, op. cit.

FOUCAULT, 2015, op. cit.

FERRARI; CAETANO, 2012, op. cit.

FOUCAULT, 2015, op. cit., p. 48.

0 uso do termo "homossexualismo" aqui deve ser entendido vinculado a seu contexto histórico. Destarte, a fim de evitar quaisquer interpretações equivocadas e/ou deslocadas temporalmente, fazemos o uso desse termo entre aspas ao longo do texto a fim de indicar sua inadequação na atualidade. LOMANDO; WAGNER, 2009, op. cit.

Idem.

Idem.

FERRARI; CAETANO, 2012, op. cit.

Idem, p. 19.

RUSSO, Jane. 0 campo da sexologia e seus efeitos sobre a política sexual. In: CORRÊA, Sonia; PARKER, Richard (orgs.). Sexualidade e política na América Latina: histórias, intersecções e paradoxos. Rio de Janeiro: Abia, 2011.

Idem, p. 175.

CAMARGO JR., Kenneth de. 0 paradigma clínico-epidemiológico ou biomédico. Revista Brasileira de História da Ciência, v. 6, n. 2, p. 183-195, 2013.

FERRARI; CAETANO, 2012, op. cit.

RUSSO, 2011, op. cit.

LOMANDO; WAGNER, 2009, op. cit.

RUSSO, 2011, op. cit.

LOMANDO; WAGNER, 2009, op. cit.

Idem.

LOMANDO; WAGNER, 2009, op. cit.

MOITA, 2006, op. cit., p. 66.

MOITA, 2006, op. cit.

Idem.

Idem, p. 60.

OSTERMANN, 1996, op. cit., p. 185.

OSTERMANN, 1996, op. cit.

MOREIRA; MASSONI, 2011, op. cit.

Idem, p. 33.

OSTERMANN, 1996, op. cit.

Idem.

MOREIRA; MASSONI, 2011, op. cit.

Idem.

Idem, p. 34

FERRARI; CAETANO, 2012, op. cit.

Idem, p. 18

OSTERMANN, 1996, op. cit.

MENDONÇA, 2012, op. cit.

CAMARGO JR., 2013, op. cit.

MENDONÇA, 2012, op. cit., p. 538.

KUHN, Thomas. A estrutura das revoluções científicas. São Paulo: Perspectiva, 2013. p. 83.

KUHN, 2013, op. cit., p. 119.

ABD0, Carmita. A evolução do conceito de parafilias. Debates em Psiquiatria, v. 6, n. 2, p. 36-41, 2016.

68 LAURENTI, Ruy. Homossexualismo e a classificação internacional de doenças. Revista de Saúde Pública, n. 18, v. 5, p. 344-347, 1984. 
69 ABDO, 2016, op. cit.

70 KUHN, 2013, op. cit., p. 89.

71 MENDONÇA, 2012, op. cit., p. 538.

72 KUHN, 2013, op. cit., p. 89.

73 OSTERMANN, 1996, op. cit., p. 190.

74 MOREIRA; MASSONI, 2011, op. cit.

75 KUHN, 2013, op. cit., p. 178.

76 ABDO, 2016, op. cit.

77 Idem.

78 KUHN, 2013, op. cit., p. 170.

79 LOMANDO; WAGNER, 2009, op. cit.

80 MOREIRA; MASSONI, 2011, op. cit., p. 33.

81 KUHN, 2013, op. cit., p. 170.

82 OSTERMANN, 1996, op. cit., p. 191.

83 MOREIRA; MASSONI, 2011, op. cit. p. 34.

84 KUHN, 2013, op. cit., p. 191.

85 OSTERMANN, 1996, op. cit., p. 191.

86 KUHN, 2013, op. cit., p. 190-191.

87 OSTERMANN, 1996, op. cit.

88 MOREIRA; MASSONI, 2011, op. cit., p. 35.

89 KUHN, 2013, op. cit., p. 82.

90 GUIMARÃES, Sabrina Guerra; ARAS, Lina Maria Brandão. "Distúrbios do instinto sexual" - a medicina legal define a homossexualidade, lesbianidade e transgêneros. Anais eletrônicos do Fazendo Gênero 10: Desafios atuais dos feminismos. Florianópolis: UFSC, 2013.

91 Idem, p. 4.

92 Idem, p. 7.

93 FERRARI; CAETANO, 2012, op. cit., p. 21.

[Recebido em Janeiro de 2021. Aceito para publicação em Junho de 2021] 